\title{
Application of Soft X-rays in the Decomposition of Polycyclic Aromatic Hydrocarbons (PAHs) in Smoke Particles from Biomass Fuel Burning
}

\author{
Yunhe Bai $^{1}$, Masami Furuuchi ${ }^{1 *}$, Perapong Tekasakul ${ }^{2}$, Surajit Tekasakul ${ }^{3}$, \\ Thitiworn Choosong ${ }^{1}$, Masaya Aizawa ${ }^{1}$, Mitsuhiko Hata ${ }^{1}$, Yoshio Otani ${ }^{1}$ \\ ${ }^{1}$ Graduate School of Natural Science and Technology, Kanazawa University, Kakuma-machi, \\ Kanazawa, 920-1192, Japan \\ ${ }^{2}$ Department of Mechanical Engineering, Faculty of Engineering, Prince of Songkla University, \\ Hat Yai, Songkhla 90112, Thailand \\ ${ }^{3}$ Department of Chemistry, Faculty of Science 90112, Prince of Songkla University, Hat Yai, \\ Songkhla, Thailand
}

\begin{abstract}
Soft X-rays with a wave length of $1.3 \times 10^{-4}-4.1 \times 10^{-4} \mu \mathrm{m}$ were tested for use in studying the decomposition of polycyclic aromatic hydrocarbons (PAHs), widespread hazardous and carcinogenic pollutants that are emitted during biomass burning. Both size-fractionated and -unfractionated smoke particles, after irradiation by the soft X-rays, were collected on quartz-fiber filters using two different residence times through the irradiating zone to determine the effect of the soft X-ray irradiation on particle-bound PAH concentration. Smoke particles produced by rubberwood burning had a single modal size distribution consisting of fine particles less than $2 \mathrm{~m}$ and a large mass fraction of PAHs in particles that were about 5 times higher than the urban ambient particles. The PAHs in the rubberwood smoke were decomposed by soft X-ray irradiation up to about $30 \%$, essentially independent of the duration of the irradiation $(0.022-0.067 \mathrm{sec})$ and with a slight dependence on the boiling temperature of each PAH composition. From the irradiation test for the size fractionated particles, PAHs in finer fraction particles were found to be decomposed more effectively. Soft X-rays have the potential for use as an effective device for pollution control.
\end{abstract}

Keywords: PAHs; Decomposition; Biomass burning; Irradiating duration; Particle size; Rubberwood.

\footnotetext{
* Corresponding author. Tel.: +81-76-234-4646, Fax: +81-76-234-4644

E-mail address: mfuru@t.kanazawa-u.ac.jp
} 


\section{INTRODUCTION}

Soft X-rays have recently been used as an effective neutralizer or charge inducer of aerosol particles (Inaba et al., 1994; Kulkarni et al., 2002; Han et al., 2003). Because soft X-rays have a high radiation energy which may degrade some chemical components, it is important to evaluate how the irradiation influences the charging process. This may be crucial in terms of the chemical composition of an ultra-fine atmospheric aerosol after sizing the particles by an electrostatic method, such as differential mobility analyzer (DMA) (Willeke et al., 1993; Hinds, 1999), because these particles are generated largely from anthropogenic sources and contain a wide variety of degradable or volatile organic compositions, such as polycyclic aromatic hydrocarbons (PAHs) (Environmental Health Criteria, 1998; Seinfeld et al., 1998; Finlayson-Pitts et al., 1999; Spurny, 1999). From another point of view, if soft X-rays can degrade some hazardous air pollutants, it is possible that they can be used to degrade pollutants, similar to UV (Chen et al., 1996; Xiangmin et al., 1999; Sekikuchi et al., 2004). However, such degradations by soft X-rays have not been examined extensively although the authors experimentally discussed the degradation characteristics of particle-bound PAHs in ambient particles collected on a fibrous filter (Bai et al., 2006a).

Particulate emissions from biomass burning have been shown to have larger fine particulate fraction than those from fossil fuels (Hao et al., 2006; Tissari et al., 2006) and have been reported to be rich in hazardous pollutants such as polycyclic hydrocarbons (PAHs) and other carcinogenic components (Environmental Health Criteria 202, 1998; Hytoenen et al., 2006; Jokiniemi et al., 2006). Air pollutants from biomass burning are of great importance in underdeveloped and developing countries because biomass fuel is a major energy source. In Cambodia, more than $90 \%$ of the fuel for household use is wood (National Institute of Statistics, 2006) and emissions from wood and bush burning have been shown to be substantial contributors to ambient PAH concentration (Furuuchi et al., 2006a, 2006b, 2006c; Murase et al., 2006). In Thailand, the production of ribbed smoke sheet rubber (RSS) is an important industry which consumes large amounts of biomass fuels to dry wet rubber sheets in smoking rooms. About 40,000 tons/month of rubberwood are used solely in RSS production cooperatives in southern provinces in Thailand during the peak season (Tekasakul and Tekasakul, 2006; Tekasakul et al., 2006; Thai Rubber Association, 2004). Based on the authors' measurements (Tekasakul et al., 2006), the emission of 15 PAH compounds with 2-6 aromatic rings can be roughly estimated to be about 4 tons/year since most of the smoke is released into the atmosphere without any pollution control devices. Moreover, a portion of smoke leaks into the factory, where the workers are directly exposed. This is potentially harmful to the workers' health, as well as to the health of the general population, if the intake of smoke is excessive. Air pollution by hazardous components along with fine particles from biomass burning is a problem not restricted to 
developing countries, but also occurs in other countries having forest resources (Hytoenen et al., 2006; Jokiniemi et al., 2006; Tissari et al., 2006; Yli-Pirila et al., 2006;). It is associated with the utilization of biofuels in developed countries, as well.

In this study, soft X-rays with a wave length of $1.3 \times 10^{-4}-4.1 \times 10^{-4} \mu \mathrm{m}$, emitted from a commercially available soft X-ray bulb, was applied to determine whether they can be used as an effective decomposition technique for PAHs, a typical hazardous and carcinogenic pollutant emitted during biomass (rubberwood) burning. The characteristics of smoke particles, such as particle concentration, size distribution and concentration of particle-bound PAHs were examined. Both size-fractionated and total-smoke particles, after irradiation of soft X-rays, were collected on filters to determine the effect of soft X-ray irradiation on the concentration of particle-bound PAHs as a function of residence time through the irradiating zone and particle concentration.

\section{EXPERIMENTAL}

\section{Experimental setup}

Fig. 1 shows a schematic of the experimental setup, which consists of a wood-burning oven $(170 \mathrm{~cm} \times 95 \mathrm{~cm} \times 110 \mathrm{~cm})$, a soft X-ray irradiation chamber, two filter holders on the tubing from the oven along with orifice meters and manometers for flow-rate measurement and a vacuum cleaner as an air pump. Two sets of the particle collecting systems are required to study the effect of soft X-ray irradiation in comparison with non-irradiated smoke particles simultaneously. The flow rate in each sampling line is adjusted by a valve. Sampling can also be done in a single-line system, before and after the soft X-ray tube, but this has to be done in two separate experiments. Accuracy of the results will be reduced, as the concentration of wood smoke is uncontrollable. The oven is constructed of building bricks and contains a gate on one side for the wood supply. A 3-m-tall, ca. 0.2-m diameter steel tube is used as a chimney for the flue gas exhaust. The setup is installed on the grounds of the campus of the Prince of Songkla University, Thailand (PSU). Rubberwood is burned as a biomass fuel in the oven and a portion of the flue gas is then introduced into the irradiation chamber at a constant flow rate adjusted by a valve downstream of the filter holder where the smoke particles are collected on a quartz-fiber filter (ADVANTEC, QR-100, $110 \mathrm{~mm}$ ). Smoke particles from the oven were also sampled using two sets of 8-stage cascade (Andersen) impactors (Tokyo Dylec, AN-200) to evaluate the characteristics of smoke particles, including the concentration, size distribution and chemical composition. When cascade impactors are used, they simply replace the filter holders and vacuum cleaner as shown in Fig. 1. The filter used for particle collection by the cascade impactors is an identical quartz-fiber filter (ADVANTEC, QR-100, $80 \mathrm{~mm}$ ). 


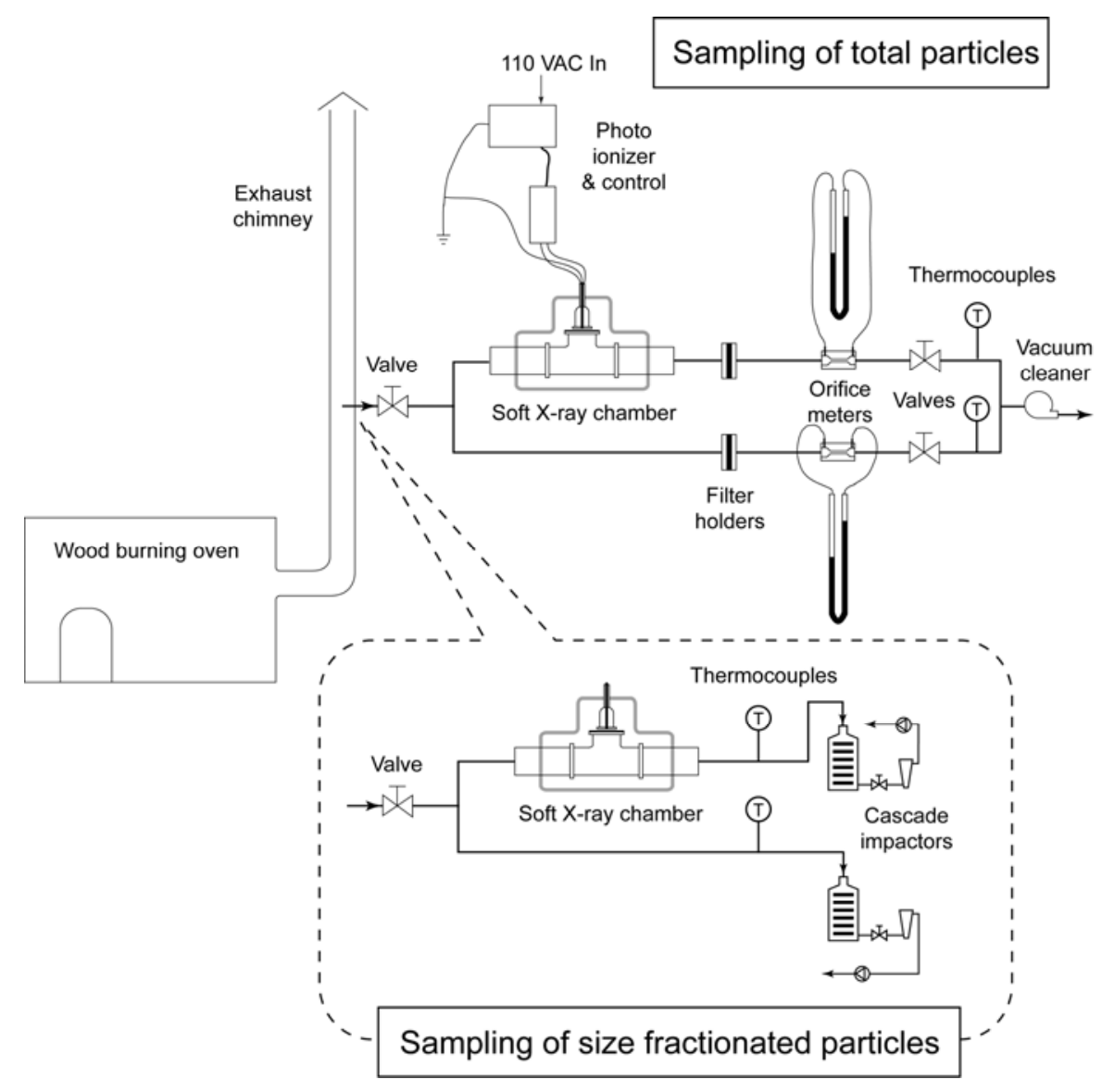

Fig. 1. Experimental setup.

Fig. 2 shows the detail of the irradiation chamber. A soft X-ray tube (Hamamatsu Photonics Photo Ionizer ${ }^{\circledR}$ L6941) with a wavelength of $1.3 \times 10^{-4}-4.1 \times 10^{-4} \mu \mathrm{m}$, average intensity of 4.4 $\mathrm{keV}$ at $4-\mathrm{cm}$ distance is positioned on the top of the irradiation chamber, consisting of a $\mathrm{T}$-shaped steel tubing joint shielded with a 6-mm-thick PVC T-joint where soft X-rays can easily be shielded by a 5-mm-thick PVC sheet or a 0.8 -mm-thick stainless steel sheet (Hamamatsu Photonics, 2006). In order to avoid direct exposure of the soft X-ray bulb surface to the flue gas and water vapor, the top end of the inner (steel) T-joint is covered by a $25-\mu \mathrm{m}$-thick high radiation and thermal resistant polyimide film (DuPont, Kapton ${ }^{\circledR}, \mathrm{H} 100$ ). All steel parts of the chamber assembly were rinsed with acetone and then cleaned using ultra-pure water in order to avoid any volatile matters being emitted during the irradiation. 


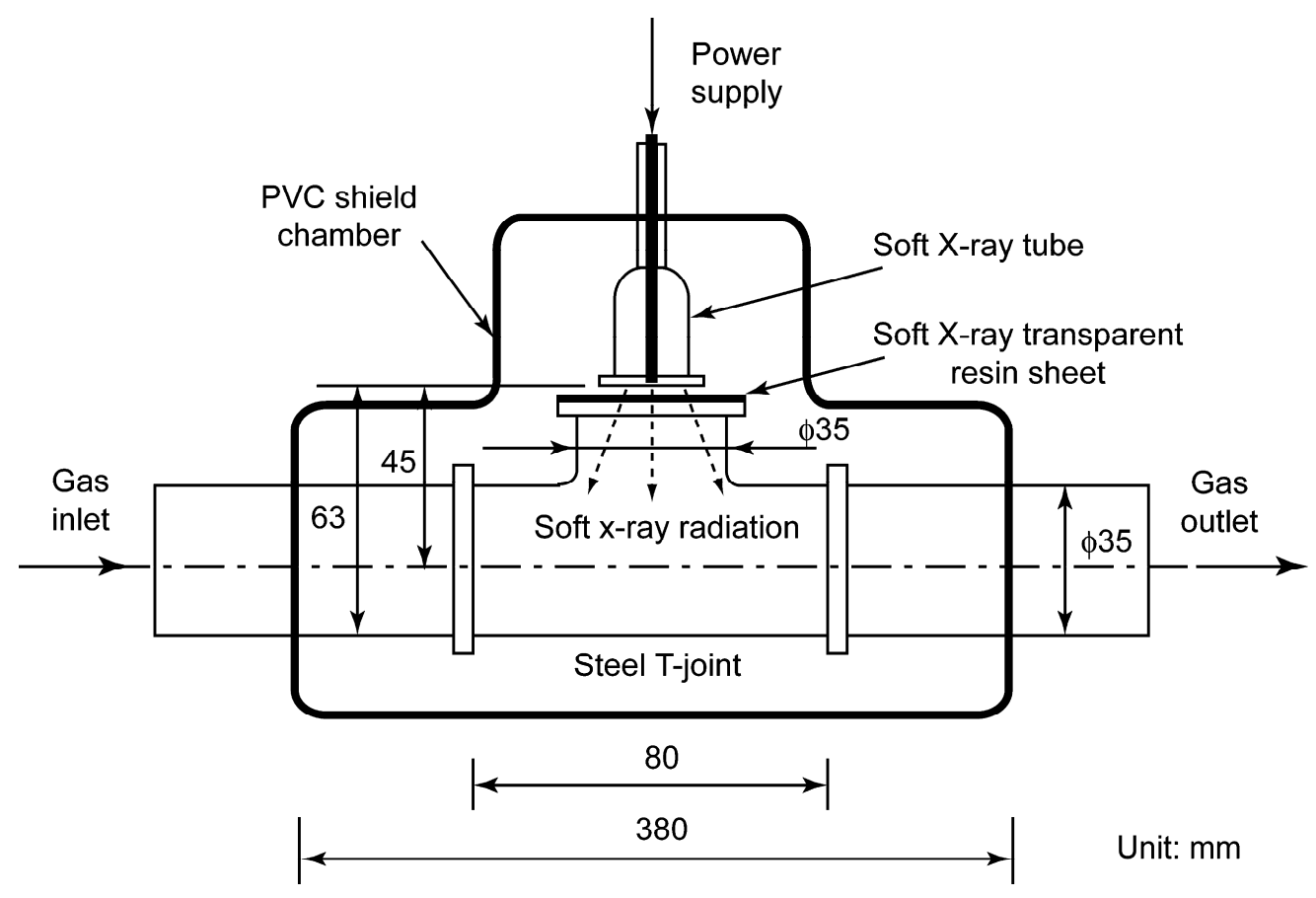

Fig. 2. Details of the irradiation chamber and specification of the irradiation zone (unit in millimeters).

The separation of the soft X-ray tube surface from the chamber bottom and from the tube center is 63 and $45 \mathrm{~mm}$, respectively. The area irradiated by soft X-rays is actually a circular area with a diameter of $35 \mathrm{~mm}$, equal to the diameter of the tube. Hence, the residence time through the chamber is defined here as the time required for a sample to pass through the tube diameter $(35 \mathrm{~mm})$. Based on laboratory measurement of soft X-ray energy using an ion chamber survey meter (Aloka, ICS-321, 1-cm dose equivalent rate measurement), the average energy level $E$ of a soft X-ray can be approximated by a function of distance $L(\mathrm{~cm})$ from the source as follows:

$$
E=E_{0} \exp (-\varphi \rho L)(\mathrm{keV})
$$

where $E_{0}$ is the average energy of soft X-rays $(5.20 \mathrm{keV}), \varphi$ is the total attenuation coefficient $\left(3.46 \times 10^{-3} \mathrm{~m}^{2} / \mathrm{kg}\right.$, experimentally determined) and $\rho$ is the density of air. For the distance to the tube center $(L=35 \mathrm{~mm})$, the average energy level can be evaluated as ca. $E=4.50 \mathrm{keV}$.

\section{Biomass fuel used}

The wood used in the experiment as fuel is common rubberwood, which is abundant in southern Thailand. Natural rubber trees (Hevea brasiliensis) are usually cut after 25-30 years when the rubber latex productivity reaches a low point (The Thai Rubber Association, 2004). Some of the wood is used in the furniture industry while the remainder is used as fuel in several 
industries (Office of the Rubber Replanting Aid Fund, 2006). The wood used in this experiment was in fresh condition, the moisture content of which was is $36.2 \%$ on a dry weight basis. Moisture content was determined by drying the samples in an electric oven at $110^{\circ} \mathrm{C}$. Each piece of wood is $6-$ to $10-\mathrm{cm}$ in diameter, $50-\mathrm{cm}$ long and weighs about $4 \mathrm{~kg}$.

\section{Procedure}

Initially, 4-5 pieces of rubberwood with a total weight of about $20 \mathrm{~kg}$ were fed into the oven where they were stacked up two abreast and then ignited. When the smoke concentration was visibly thin, 1-2 pieces of the wood were added to increase the smoke concentration. This situation is similar to the operation used in the RSS production cooperative (Tekasakul and Tekasakul, 2006). Since the generation of smoke decreased after the wood is largely burned, more fuelwood is repeatedly supplied at timed intervals.

Fig. 3 shows the change in smoke concentration during the test run. The particle concentration was not quite stable and decayed exponentially with time. When an additional piece of wood was supplied, the concentration increased to a high level, followed by a rapid and almost exponential decrease. There were rather stable periods after the rapid decrease. After the ignition, a portion of flue gas was sampled to the test section at two different flow rates $(30$ and $90 \mathrm{~L} / \mathrm{min}$ ) in order to examine the influence of irradiating duration. These durations were 0.022 and $0.067 \mathrm{sec}$, respectively. Reynolds numbers for the tube flow at each flow rate were ca. 1200 and 3500 respectively, corresponding to laminar and transient to turbulent regions. Particle Reynolds number defined for the average size of smoke particles $(\sim 0.62 \mu \mathrm{m})$ was much less than 0.7 for the laminar flow limit in both flow rates.

The total flow rate from the oven measured at the chimney outlet using an anemometer was confirmed to be sufficiently large (greater than $3000 \mathrm{~L} / \mathrm{min}$ ) that the influence of sampling on the main flow can be neglected. The soft X-rays were turned on when the flue gas was flowing through the test section and then turned off after the sampling. The sampling period was set to 3 $\mathrm{m}$ to avoid an excessive pressure drop through the filters. For each sampling period, the smoke particles were collected on a filter that had been pre-conditioned for $72 \mathrm{~h}$ at a constant humidity and temperature (room temperature and $\sim 50 \% \mathrm{RH}$ ) environment (Committee of Countermeasure for Suspended Particulate Matter, 1997). Sampling by the cascade impactors was started $30 \mathrm{~m}$ after the wood was fed and then continued for $15 \mathrm{~m}$. The flow rate was adjusted to a constant value (28.3 L/min, Reynolds number $\sim 1100$ (laminar)). The experimental conditions are summarized in Table 1. 


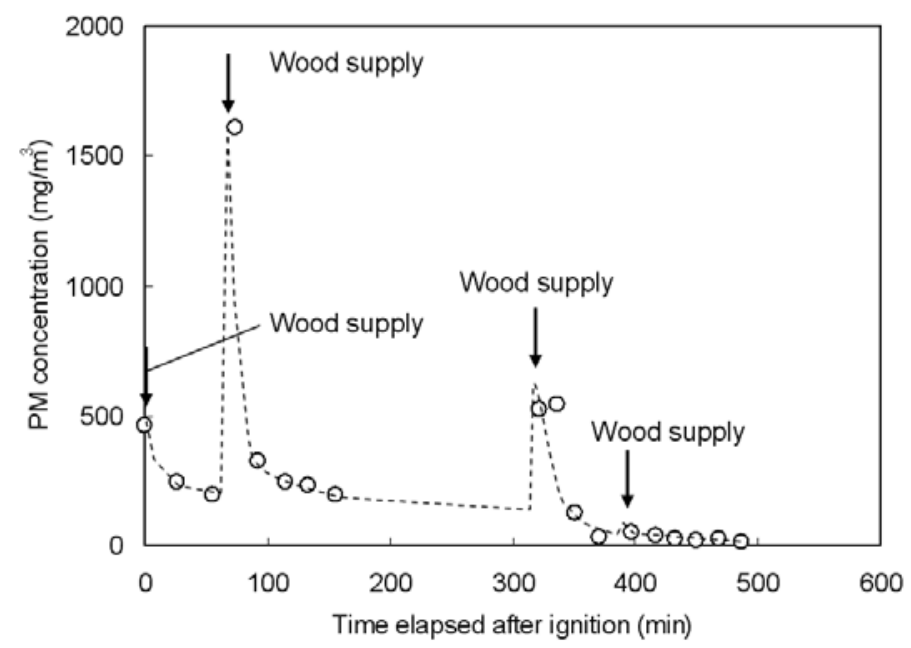

Fig. 3. Time change in smoke particle concentration during the experiment.

Table 1. Experimental conditions.

\begin{tabular}{|c|c|c|c|c|c|}
\hline \multirow{2}{*}{$\begin{array}{l}\text { Sampled } \\
\text { Particles }\end{array}$} & \multirow{2}{*}{$\begin{array}{l}\text { Flow Rate } \\
\text { (L/min) }\end{array}$} & \multirow{2}{*}{$\begin{array}{l}\text { Sampling } \\
\text { Duration } \\
\text { (min) }\end{array}$} & \multicolumn{2}{|c|}{ Number of samples } & \multirow[b]{2}{*}{ Note } \\
\hline & & & $\begin{array}{l}\text { Soft X- } \\
\text { ray OFF }\end{array}$ & $\begin{array}{l}\text { Soft X- } \\
\text { ray ON }\end{array}$ & \\
\hline $\begin{array}{l}\text { Total suspended } \\
\text { Particles }\end{array}$ & 90 & 2 or 3 & 6 & 6 & $\begin{array}{l}\text { At least } 30 \text { minutes } \\
\text { after wood feeding }\end{array}$ \\
\hline $\begin{array}{l}\text { Total suspended } \\
\text { Particles }\end{array}$ & 30 & 9 & 6 & 6 & $\begin{array}{l}\text { At least } 30 \text { minutes } \\
\text { after wood feeding }\end{array}$ \\
\hline $\begin{array}{l}\text { Size fractionatec } \\
\text { Particles }\end{array}$ & 28.3 & 30 & 2 & 2 & $\begin{array}{l}30 \text { minutes after } \\
\text { wood feeding }\end{array}$ \\
\hline
\end{tabular}

\section{Analysis of PAHs}

The collected samples were weighed after $72 \mathrm{~h}$ of conditioning and then analyzed for the concentrations of PAHs. Following the same procedure used in a previous paper (Toriba et al., 2003), 15 different PAH compounds-i.e., Naphthalene (Nap), Acenaphthene (Ace), Phenanthrene (Phe), Anthracene (Ant), Fluorene (Fle), Fluoranthene (Flu), Pyrene (Pyr), Benz[a]anthracene (BaA), Chrysene (Chr), Benzo[a]pyrene (BaP), Benzo[b] fluoranthene (BbF), Benzo[k]fluoranthene (BkF), Dibenz[a,h]anthracene (DbA), Indeno[1,2,3-cd]pyrene (IDP) and Benzo[ghi] perylene (BghiPe) —were analyzed using HPLC (HITACHI, L-2130, 2200, 2300, $2485)$ with a fluorescence detector and an Inertsil ODS-P column $(5 \mu \mathrm{m}, 4.6 \mathrm{~mm}$ diameter, 250 $\mathrm{mm}$ length) + acetonitril/ultra-pure water mobile phase after ultrasonically dissolving the samples on the filter in an ethanol/benzene (1:3) solution and evaporation on a rotary vacuum evaporator. The recovery efficiency was confirmed to be $0.82 \pm 0.12(\mathrm{n}=3)$ by adding a standard reagent (Accustandard, $0.2 \mathrm{mg} / \mathrm{mL}$ in $\mathrm{CH}_{2} \mathrm{Cl}_{2}$ : $\mathrm{MeOH}$ (1:1)) to dissolved samples (Tang et al., 2004). Reproducibility of PAHs analysis was in error of less than $1.4 \%(n=3)$. The linearity of 
the calibration curve was confirmed to be within an error of $\pm 5.7 \%$ in the range of 2 to 200 $\mathrm{ng} / \mathrm{mL}$ in the standard for all analyzed PAHs. Travel blank values of PAHs were subtracted from analyzed values.

\section{RESULTS AND DISCUSSION}

\section{Characteristics of smoke particles from rubberwood burning}

Fig. 4 shows the size distribution of smoke particles from the rubberwood burning smoke (Furuuchi et al., 2006a). It contains major particles in the accumulation mode, similar to other cases of biomass burning (Hao et al., 2006; Tissari et al., 2006). Fig. 5(a) shows the summed up concentration of PAHs with 2-6 aromatic rings in each size range. Compared with ambient particles in the city central of Hat Yai, Thailand (Furuuchi et al., 2006a), the concentration of PAHs in the smoke particles is extremely high especially in fine fractions less than 2-3 $\mu \mathrm{m}$. Fig. 5(b) shows the mass fraction of PAHs for each size range of particles. Smoke particles from rubberwood burning make up ca. 5 times larger portion in size average than urban ambient particles, indicating that the rubberwood is a serious emission source of PAHs. Fig. 6 shows PAH profiles on a mass fraction basis, where Nap is not shown because of a less reliability on the concentration. Large fractions of Phe, Flu and Pyr are consistent with previously reported results (Furuuchi et al., 2006b), where Flu and Pyr are typical compositions emitted from biomass burning (Environmental Health Criteria 202, 1998).

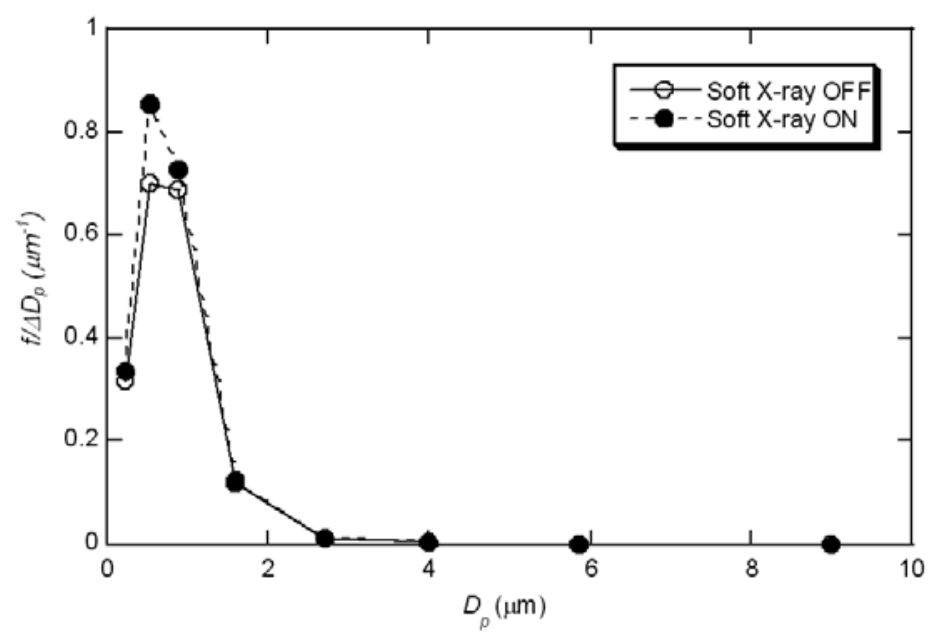

Fig. 4. Size distribution of smoke particles. 

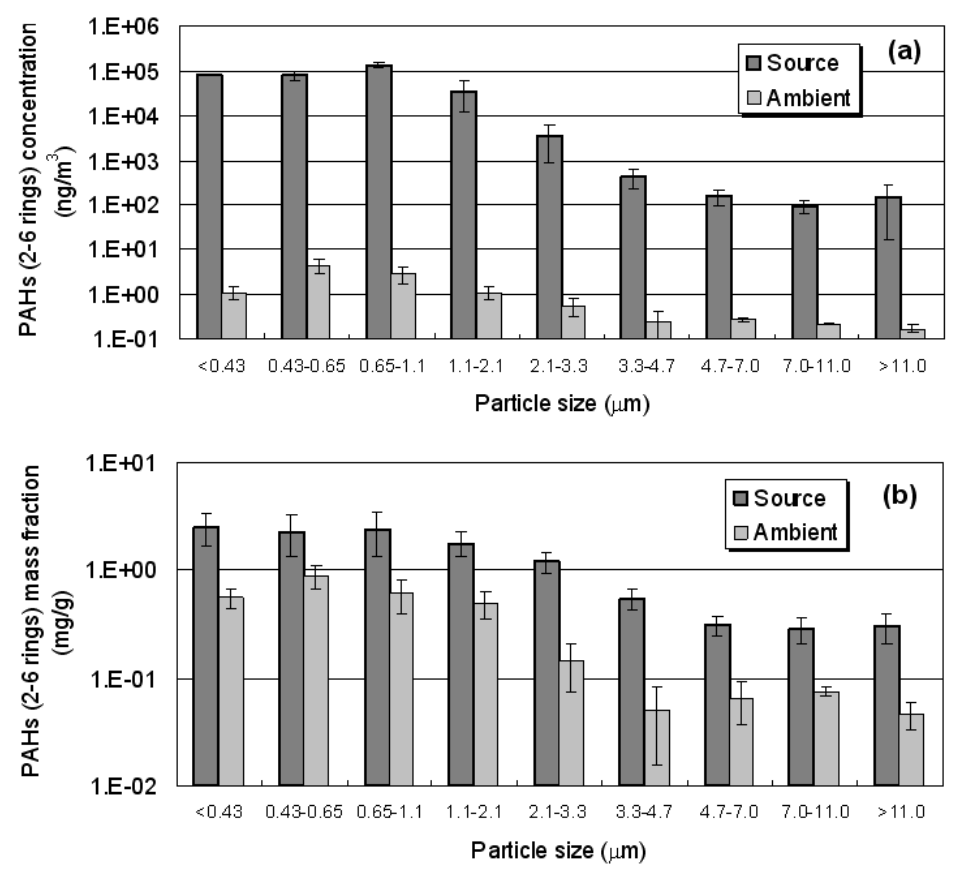

Fig. 5. Examples of concentration (a) and mass fraction (b) of PAHs with 2-6 aromatic rings for each size range of particles, where the number of samples is 2 for the source (average smoke particle concentration $=353 \pm 21 \mathrm{mg} / \mathrm{m}^{3}$ ) and 4 for the ambient.

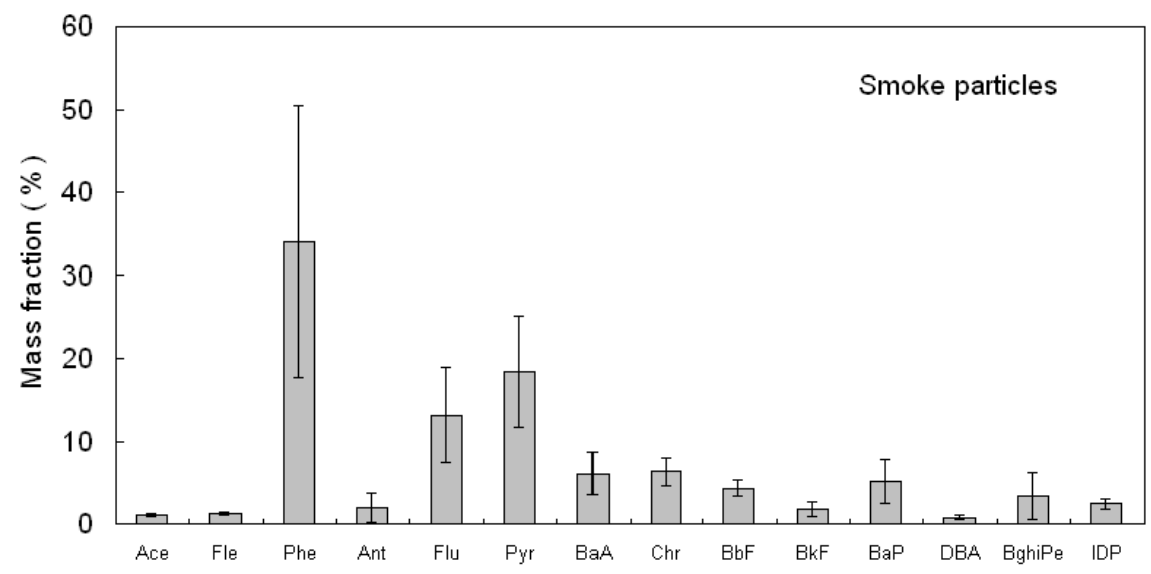

Fig. 6. The mass fraction of each PAH in the total smoke particles $(n=4)$.

Fig. 7 shows the relation between smoke concentration and the mass fraction of PAHs with 4-6 rings in total smoke particles, where the soft X-rays are turned off. Although there are fluctuations $\sim 30 \%$, the mass fraction of the PAHs in the smoke particles is rather constant except for the period soon after wood supply. Hence, in the following sections, characteristics of the PAHs in the samples during the stable burning period obtained at least 30 minutes after wood 
supply, are discussed.

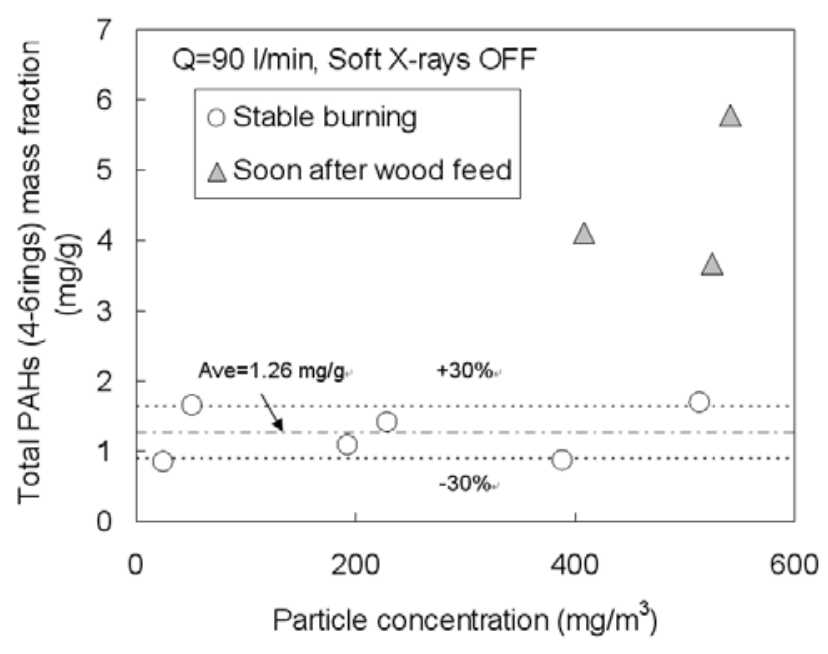

Fig. 7. Mass fraction of each PAHs in relation to smoke particle concentration.

\section{Decomposed fraction of PAHs}

Fig. 8 shows the influence of the average mass fraction of each PAH composition in particles after soft X-ray irradiation compared with the case of non irradiation for a flow rate $Q=90 \mathrm{~L} / \mathrm{min}$. The mass fractions of each of the PAHs are reduced as the result of the soft X-ray irradiation. The decomposition of PAHs at a flow rate of $30 \mathrm{~L} / \mathrm{min}$ is similar. Fig. 9 shows the decomposed fraction $\eta$ plotted against the boiling temperature of each PAH composition, where $\eta$ is defined as

$$
\eta=\left(M_{f}-M_{i}\right) / M_{f}
$$

where $M_{i}$ is the mass fraction of PAHs in particles when the soft X-rays are $\mathrm{ON}$, and $M_{f}$ is that when the soft X-rays are OFF. Here, the mass fraction of PAHs is used to minimize the influence of fluctuations in particle concentration. Although a fluctuation exists, values are similar for the different flow rates and smoke concentrations and seems to decrease as the boiling temperature increases. Such behavior regarding boiling temperature is similar to the soft X-ray decomposition of PAHs in particles collected on the filter (Bai et al., 2006a). The total decomposition reaches around $30 \%$, regardless of the flow rate. The slight influence of flow rate suggests that the irradiating duration corresponding to both flow rates is already sufficient to be decomposed by the soft X-rays to some limit from the present configuration although a much longer duration could increase the decomposition as shown for PAHs in particles collected on the filter (Furuuchi et al., 2005b; Bai et al., 2006a). 


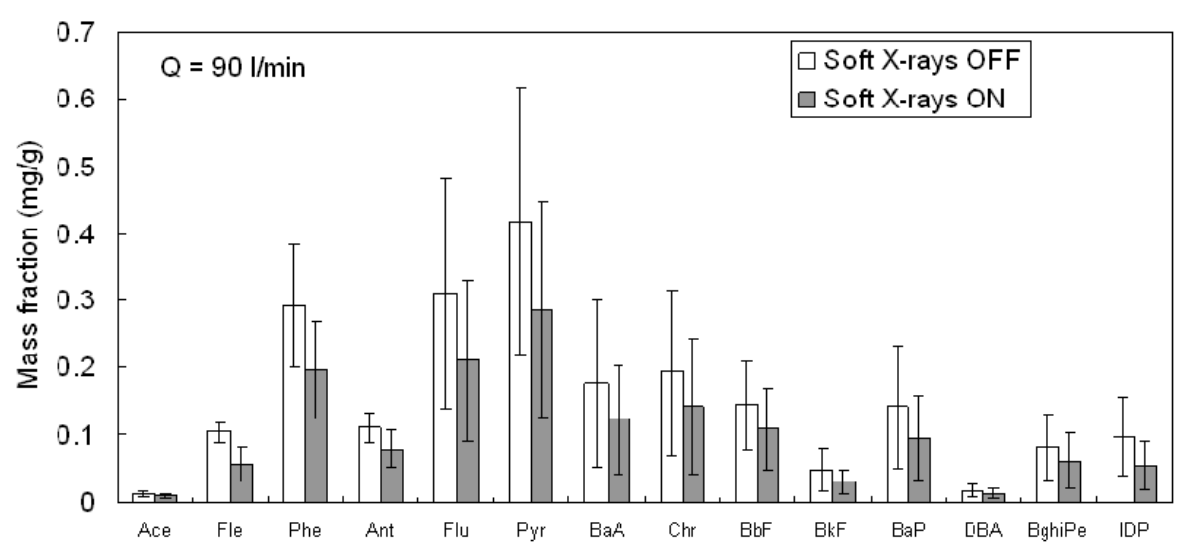

Fig. 8. The average mass fraction of each $P A H$ composition in particles after soft X-ray irradiation compared with the average value for non-irradiated samples.

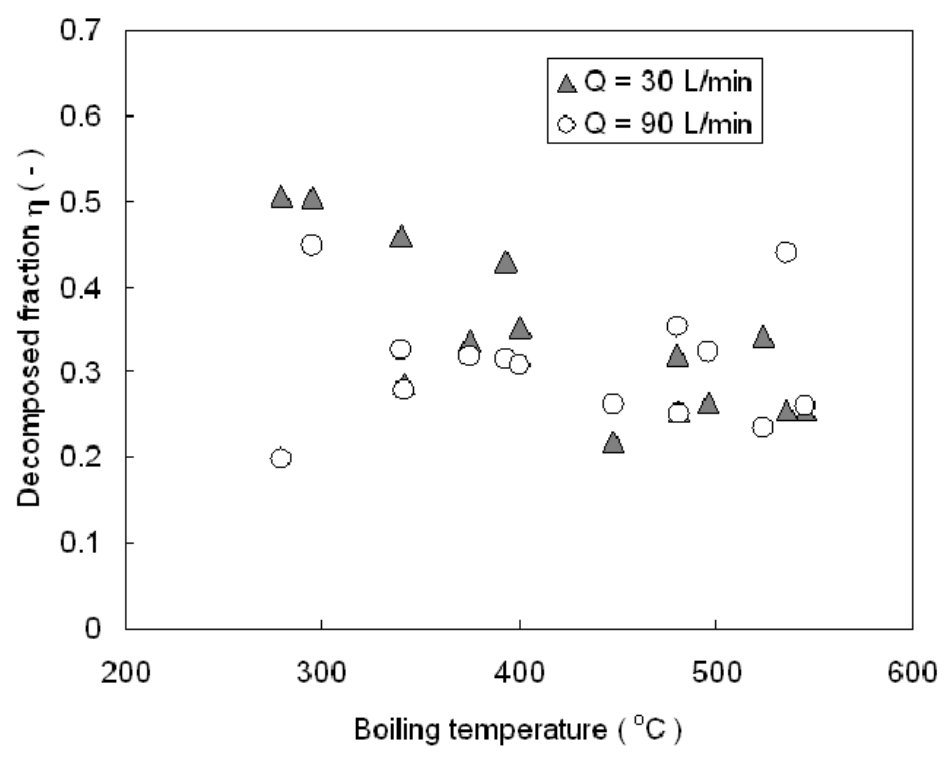

Fig. 9. Relation between the boiling temperature of each $\mathrm{PAH}$ composition and fraction decomposed $\eta$.

The pattern of gas flow through the irradiation zone, as well as the flow around particles, may also affect the decomposition if the reaction is limited by the diffusion of radicals or chemicals generated by the soft X-rays irradiation; an increase in Reynolds number might accelerate the decomposition. However, the difference was not clear under the present condition. This should be confirmed for different flow patterns under the same irradiating conditions (duration and energy). The decomposition should also be accelerated by decreasing the distance between the soft X-rays and working fluid because of the increase in the soft X-ray energy (Bai et al., 2006b).

The energy consumption to decompose PAHs (2-6 rings) by the soft X-rays using the present 
configuration is estimated, e.g., as ca. $6.5 \mathrm{kWh} / \mathrm{g}$-PAHs for the condition of particle concentration $=350 \mathrm{mg} / \mathrm{m}^{3}, 3 \mathrm{mg} / \mathrm{g}$ of PAHs (2-6 rings) mass fraction, $\eta=30 \%$ and $90 \mathrm{~L} / \mathrm{min}$ of the flue gas flow rate (average experimental conditions, approximately). For more effective decomposition, an increase in the total energy of soft X-rays to PAHs is important. In order to do this, a larger capacity of soft X-ray bulb, shorter and uniform distance between the bulb and target aerosol making use of an irradiation duct with slit-shaped cross-section, double or triple bulbs configured in line along the gas flow direction and a slower gas velocity may be applicable. However, detailed information on influences of parameters, such as the energy of soft X-rays (distance), irradiating duration (residence time), flow pattern (flow rate) and particle concentration, etc. have to be obtained first. These will be confirmed in the future work.

\section{Influence of size of smoke particles}

Fig. 10 shows the influence of the soft X-ray irradiation on the mass fraction of each PAH obtained for the size-fractionated sampling. The distribution of PAHs are similar to those shown in Fig. 8 for the total suspended smoke particles. The total decomposed fraction of the total PAHs $(\sim 27 \%)$ is also similar, confirming the behavior of soft X-ray irradiation although more sized samples should be obtained to increase the statistical reliability of these conclusions. Fig. 11 shows the relationship between the fraction of 3 rings (Ace, Fle, Phe, Ant), 4 rings (Flu, Pyr, BaA, Chr), 5-6 rings (BaP, BbF, BkF, DbA, IDP, BghiPe) and 3-6 rings of PAHs decomposed, as well as particle size. It is clear that the fraction that is decomposed increases as the particle size decreases. This may be related to the fact that ultra-fine smoke particles contain more PAHs, as shown in Fig. 5 and as reported previously (Furuuchi et al., 2005a; Tekasakul et al., 2006). In addition, it is possible that soft X-ray irradiation is more effective for finer particles because of its limited permittivity deep inside the particles. This will be confirmed in future work.

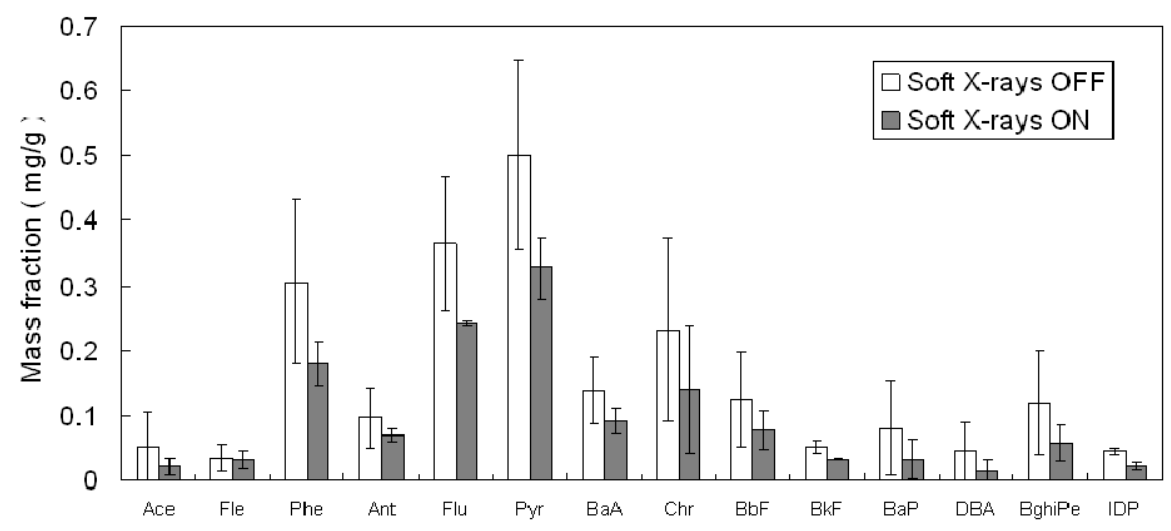

Fig. 10. Effect of soft X-ray irradiation on the mass fraction of PAHs in particles collected by cascade impactors. 


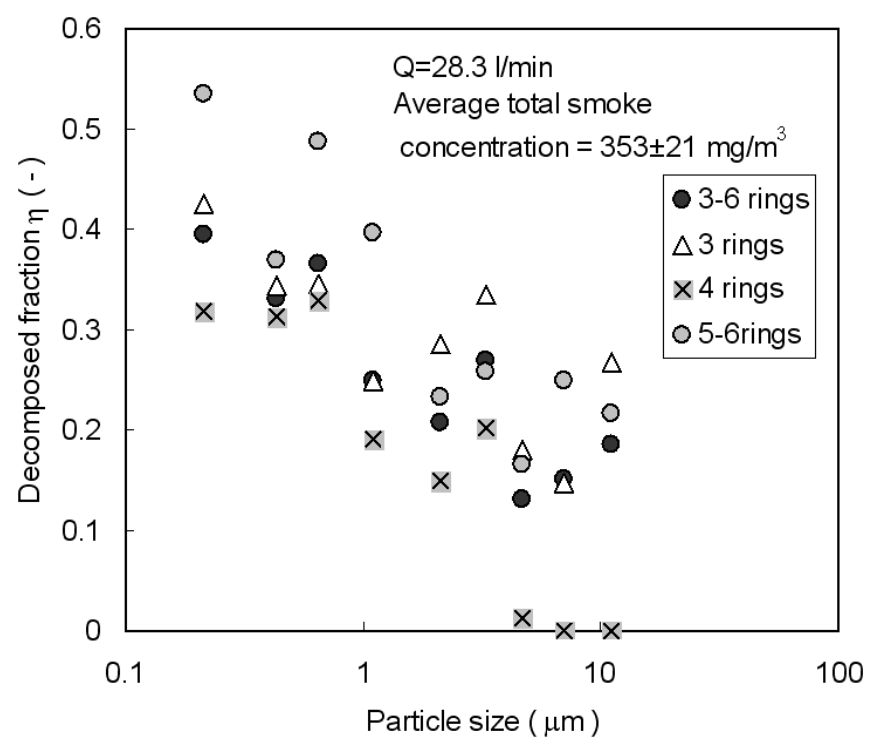

Fig. 11. Influence of soft X-ray irradiation on the fractions of PAHs in size fractionated samples.

\section{CONCLUSION}

The smoke particles from the rubberwood burning were shown to have a single modal size distribution consisting of fine particles less than $2 \mu \mathrm{m}$ and a large mass fraction of PAHs in particles about 5 times higher than urban ambient particles. PAHs in smoke from rubberwood burning were decomposed by soft X-ray irradiation up to about $30 \%$ regardless of the duration of the irradiating $(0.022-0.067 \mathrm{sec})$ and with a slight dependence on the boiling temperature of each PAH composition. From the irradiation test using size-fractionated particles, the PAHs in finer fraction particles were found to be more effectively decomposed. Soft X-rays were shown to be potentially useful as an effective device for pollution control while the large loss in chemicals will also become a problem when the soft X-ray is used as a neutralizer or a charger of aerosol particles.

\section{AKNOWLEDGMENT}

The authors would gratefully acknowledge The Japan Society for the Promotion of Science (JSPS) and National Research Council of Thailand (NRCT) for the 2006 Joint Research funding and also acknowledge Mr. Naret Jindapet, Mr. Chalad Yuenyao and Ms. Jiraporn Chomanee for experimental assistance. 


\section{REFRENCES}

Bai, Y., Furuuchi, M., Panyamethekul, S., Otani, Y., Limpaseni, W., Hata, M. and Aizawa, M. (2006a). Degradation Characteristics of PAHs in Ambient Particulates for Soft X-ray Irradiation. J. Ecotechnology Res. 12: 126-129.

Bai, Y., Furuuchi, M., Otani, Y., Hata, M., Aizawa, M. and Panyametheekul, S. (2006b). Decomposition of PAHs in ambient PM by soft X-ray irradiation. Proc. $7^{\text {th }}$ Int. Aerosol Conf., St. Paul, USA: 310-312.

Chen, J.W., Kong, L.R., Zhu, C.M., Huang and Wang, L.S. (1996). Correlation between Photolysis Rate Constants of Polycyclic Aromatic Hydrocarbons and Frontier Molecular Orbital Energy. Chemosphere. 33: 1143-1150.

Committee of Countermeasure for Suspended Particulate Matter. (1997). Pollution Prediction Manual for Suspended Particulate Matter (in Japanese), Toyokan, Tokyo, p. 371.

Environmental Health Criteria 202, International Programme on Chemical Safety, United Nations Environmental Programme, International Labor Organization, World Health Organization, (1998).

Finlayson-Pitts, B.J. and Pitts, J.N., Jr. (1999). Chemistry of the Upper and Lower Atmosphere, Academic Press, San Diego, p. 436-466.

Furuuchi, M., Sakano, T., Kizu, R., Shimizu, Y. and Okubo et al. (2005a). PAHs in Ultra-fine Ambient Aerosol Sampled by a Supersonic Impactor (in Japanese). J. Aerosol Res. 20: 135-142.

Furuuchi, M., Bai, Y., Panyametheekul, S., Otani, Y., Limpaseni, W. and Sakano, T. (2005b).

Degradation of PAHs in Ambient Particulates using Soft X-ray. Proc. Asian Aerosol Conference (AAC) 2005, Dec.13-16, Mumbai, India: 340-342.

Furuuchi, M., Tekasakul, P., Otani, Y., Tekasakul, S., Sakano, T., Bai, Y. and Murase, T. (2006a). Characteristics of Particulates Emitted from Rubber Wood Burning. J. Ecotechnology Res. 12: 135-139.

Furuuchi, M., Murase, T., Yamashita, M., Oyagi, H., Sakai, K., Tsukawaki, S., Sieng S. and Hata, M. (2006b). Temperature Distribution and Air Pollution in Phnom Penh, Cambodia - Influence of Land Use and the Mekong and Tonle Sap Rivers. Aerosol Air Qual. Res. 6: 134-149.

Furuuchi, M., Murase, T., Tsukawaki, S., Hang, P., Sieng, S. and Hata, M. (2006c). Characteristics of Air Pollutants in Angkoe Monuments Area, Cambodia. Proc. $7^{\text {th }}$ International Aerosol Conference, St. Paul, USA: 1723-1724.

Hamamatsu Photonics. (2006). Photo Ionizer® L6941 Operating Manual.

Han, B., Shimada, M., Okuyama, K. and Choi, M. (2003). Classification of Monodisperse Aerosol Particles using an Adjustable Soft X-ray Charger. Powder Technology. 39: 336-344.

Hao, L., Duan L., Duan J., Guo, X. and Yi, H. (2006). Fine Particle Emissions from Rural 
Household Biofuel Combustion in China. Proc. $7^{\text {th }}$ International Aerosol Conference, Sep.10-15, St. Paul, Minnesota, USA: 250-251.

Hinds, William C. (1999). Wiley-Interscience, New York, Aerosol Technology, p. 343-344.

Hytoenen, K., Tissari, J., Yli-Pirilla, P. and Jokiniemi, J. (2006). PAH Emissions from a Masonry

Heater in Small Scale Wood Combustion. Proc. $7^{\text {th }}$ International Aerosol Conference, Sep.10-15, St. Paul, Minnesota, USA: 245-246.

Inaba, H., Ohmi, T., Yoshida, T, and Okada, T. (1994). Neutralization of Static Electricity by Soft X-rays and Vacuum UV Irradiation. J. Electrostatics. 33: 15-42.

Jokiniemi, J., Lyyraenen, J. and Tapper, U. (2006). Fine Particle Characterization by Electron Microscopy in a Small Scale Masonry Heater During Poor and Good Combustion Condition: Proc. $7^{\text {th }}$ International Aerosol Conference, Sep.10-15, St. Paul, Minnesota, USA: 244-245.

Kulkarni, P., Namiki, N., Otani, Y. and Biswas, P. (2002). Charging of Particles in Unipolar Coronas Irradiated by in-situ Soft X-rays Enhancement of Capture Efficiency of Ultrafine Particles. J. Aerosol Sci. 33: 1279-1296.

Murase, T., Furuuchi, M. Tsukawaki, S., Sieng, S., Hata, M. and Yamashita, M. (2006). Present Status and Characteristics of Ambient Air Pollution in Phnom Penh, Cambodia (in Japanese). J. Aerosol Res. 21: 101-107.

National Institute of Statistics, Ministry of Planning, Cambodia. (2005). Main Source of Cooking Fuel, Main Source of Light, 1998 Population Censes of Cambodia.

Office of the Rubber Replanting Aid Fund, Ministry of Agriculture and Cooperatives (http://www.rubber.co.th)

Sekikuchi, K., Juyoung, J. and Sakamoto, K. (2004). Removal of Organic Contaminations by the Reduction of Labic Species using Different Wavelength of Radiation from a Single UV Source. J. Aerosols Res. 19: 188-195.

Seinfeld, J. H. and Pandis, S. N. (1998). Atmospheric Chemistry and Physics, Wiley Interscience, New York, pp.111, 700-702.

Spurny, K.R. (1999). Anal. Chem. Lewis Pub., New York, p. 61- 66.

Tang, N. Hattori, T., Taga, R., Igarashi, K., Yang, X., Tamura K., Kakimoto, H., Mishukov, V. F., Tproba, A., Kizu, R. and Hayakawa, K. (2005). Polycyclic Aromatic Hydrocarbons and Nitropolycyclic Aromatic Hydrocarbons in Urban Air Particulates and Their Relationship to Emission Sources in the Pan-Japan Sea Countries. Atmos. Environ. 39: 5817-5826.

Tekasakul, P. and Tekasakul, S. (2006). Environmental Problems Related to Natural Rubber Production in Thailand. J. Aerosol Res. 21: 122-129.

Tekasakul, P., Furuuchi, M., Tekasakul, S., Otani, Y., Tsukawaki, S., Jinno, T. and Murase, T. (2006). Environmental Impacts of Particulates Emitted from Rubber-wood Burning in Rubber Smoked Sheet Production in Thailand: Proc. $7^{\text {th }}$ International Aerosol Conference, St. Paul., USA: $1526-1528$. 
The Thai Rubber Association, TRA Directory, p. 15-19. (2004).

Tissari, J., Hytoenen, K., Yliprilla, P., Suonmaa, V., Turrek, T., Willman, P. and Jokiniemi, J. (2006). Emission Comparison of the Poor and Good Combustion of Wood in the Small Masonry Heater. Proc. $7^{\text {th }}$ International Aerosol Conference, Sep.10-15, St. Paul, Minnesota, USA: 252-253.

Toriba, A., Kuramae, Y., Chetiyanukornkul, T., Kizu, R., Makino, T., Nakazawa, H., and Hayakawa, K. (2003). Quantification of Polycyclic Aromatic Hydrcarbons (PAHs) in Human Hair by HPLC with Fluorescence Detection: A Biological Monitoring Method to Evaluate the Exposure to PAHs. Biomed. Chromatogr. 17: 126-132.

Willeke, K., and Baron, P.A. (1993). Aerosol Measurement, John Wiley \& Sons, New York, p. 126-127.

Xiangmin, P., Limin, C. and Yu, C. (1999). Photodegradation of PAHs in Aerosols Sorbed on Quartz Filters, J. Fudan University (Natural Science). 38: 119-123.

Yli-Pirila, P., Sippula, O., William, P. and Jokiniemi, J. (2006). Particle Emission from Two District Heating Units Operating on Biofuel and Heavy Fuel Oil. Proc. $7^{\text {th }}$ International Aerosol Conference, Sep.10-15, St. Paul, Minnesota, USA: 242-243.

Received for review, November 8, 2006

Accepted, January 10, 2007 